Historic, archived document

Do not assume content reflects current scientific knowledge, policies, or practices. 


\section{berme, 403}

Ag $84 \mathrm{~L}$

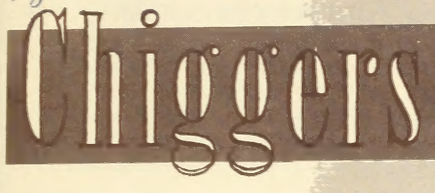

\section{HOW}

TO

FIGHT

THEM

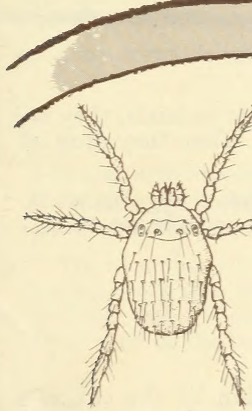

LEAFLET NO. 403

U. S. DEPARTMENT OF AGRICULTURE

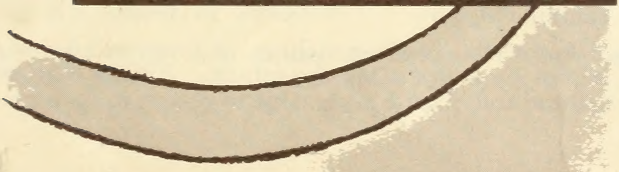





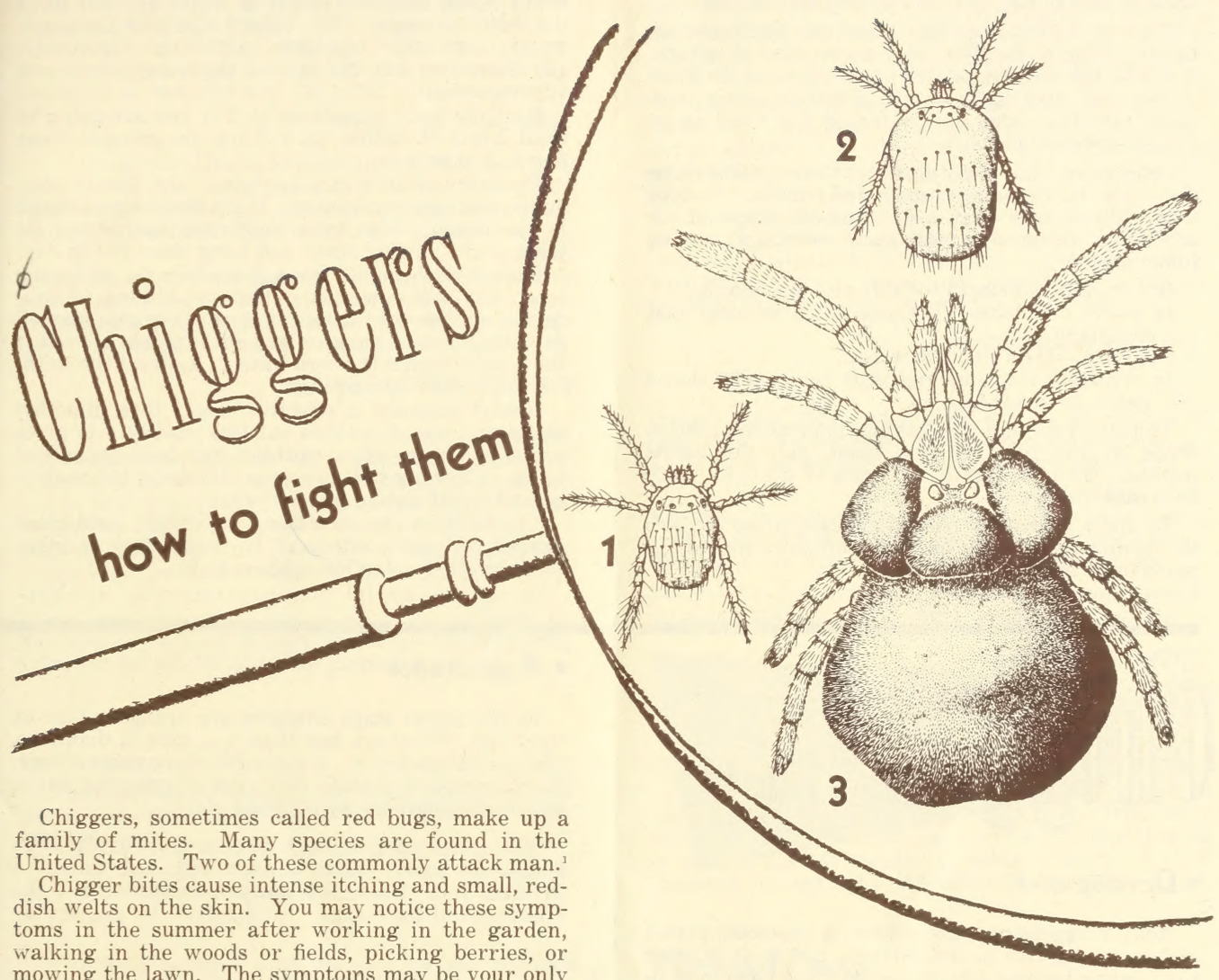

ing the lawn. The symptoins may be your only way of knowing that you have been in an infested place, because chiggers are so small that most persons cannot see them without a magnifying glass.

The pests occur in Nebraska, Iowa, Illinois, Indiana, Ohio, and Pennsylvania, and in all States farther south. They are especially troublesome in the South.

You can use a repellent to prevent attacks by chiggers if you go in an area known to be infested. If you get in an infested area without knowing it, you can reduce itching by bathing and by applying an antiseptic and a local anesthetic to the welts. You can get rid of an infestation by spraying or dusting the infested area with an insecticide.

\section{A Species of Chigger}

(Eutrombicula batatas)

1. Unengorged larva

2. Engorged larva

3. Adult

\footnotetext{
${ }^{1}$ Eutrombicula batatas and $E$. alfreddugèsi.
}

From Michener. Ann. Ent. Soc. Amer. 1946. 
HOW TO PREPARE SPRAYS FOR CHIGGER CONTROL

Forms in which insecticides may
be purchased

Chlordane or Toxophene

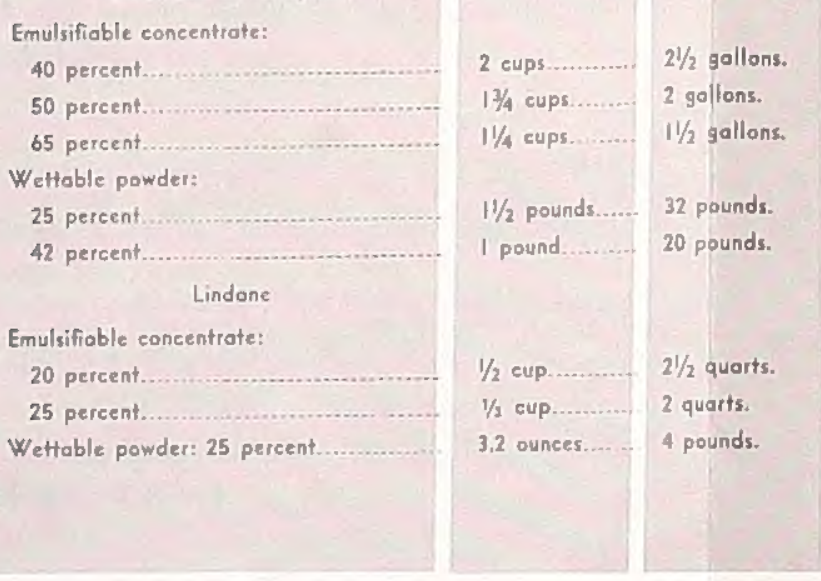

Precautions

Repellents

Do not treat underweat with a repellent. Treated underDo not apply a repellent to stockings or other clothing ond to some other manmade fibersi nylon is not domaged. Do not let repellents touch painted surfoces or objects
made of plostic materials, such os fountain pens, fishing rods, wateh crystal $s_{1}$ or fromes of eyeglosses.

Insecticides

Chlordane, toxaphene, and lindane are poisons. Handle
them with care. Wear heovy clothing when you apply them. If if ore. emulsifiable concentrate spills on your stin, wash it off at once with saop and water.
Avoid breothing the sproy or dust. Spray or dust with Keep children and pets out of a treated area until the spray dries.
After treating o lawn, sprinitle it with woter to wosh the After freating o lawn, sprinke it with woter to wash the
insecticide from the grossinto the soil. This reduces the
hazard to children and pets, and does not reduce the Do not allow livestock to groze on o treated area within 2 weeks ofter the treatment. To avoid killing fish, do not apply foxaphene olong the morgins of lakes or ponds, or olong the banks of streams.
Lindone or chlordane may be used in these places, but avoid contaminoting the water.
Do not opply insecticide to your skin or your clothing to
repel or kill chiggersi use only recommended repellents in
this

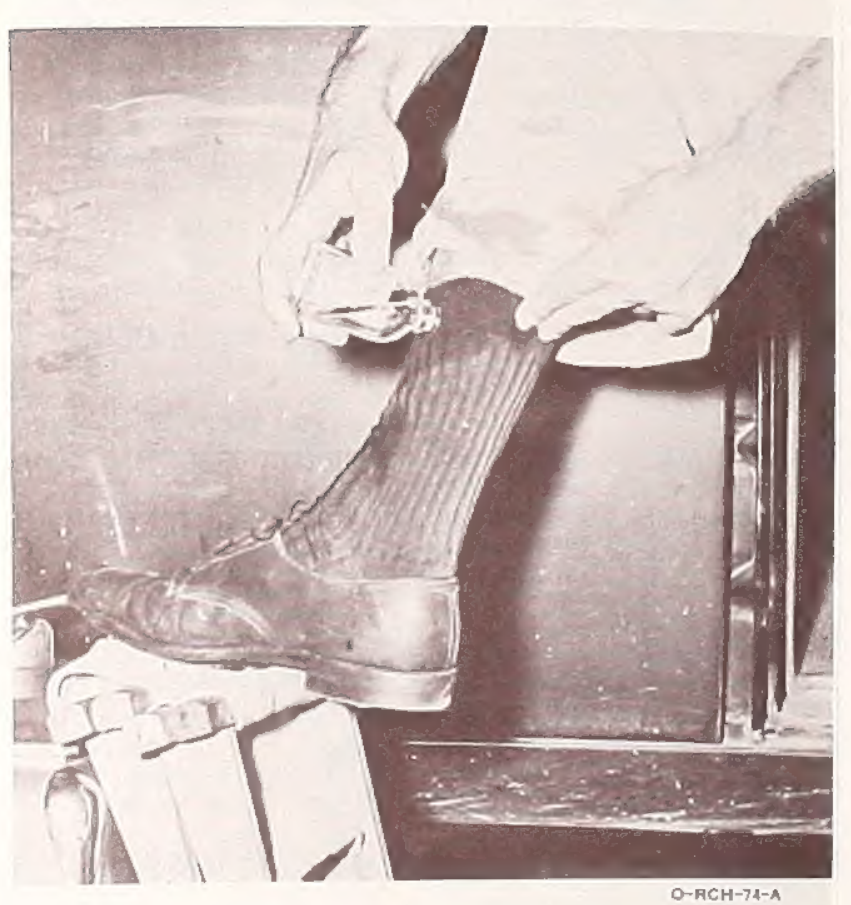

Applying repellent to socks and culfs of trousers for protection against chiggers.

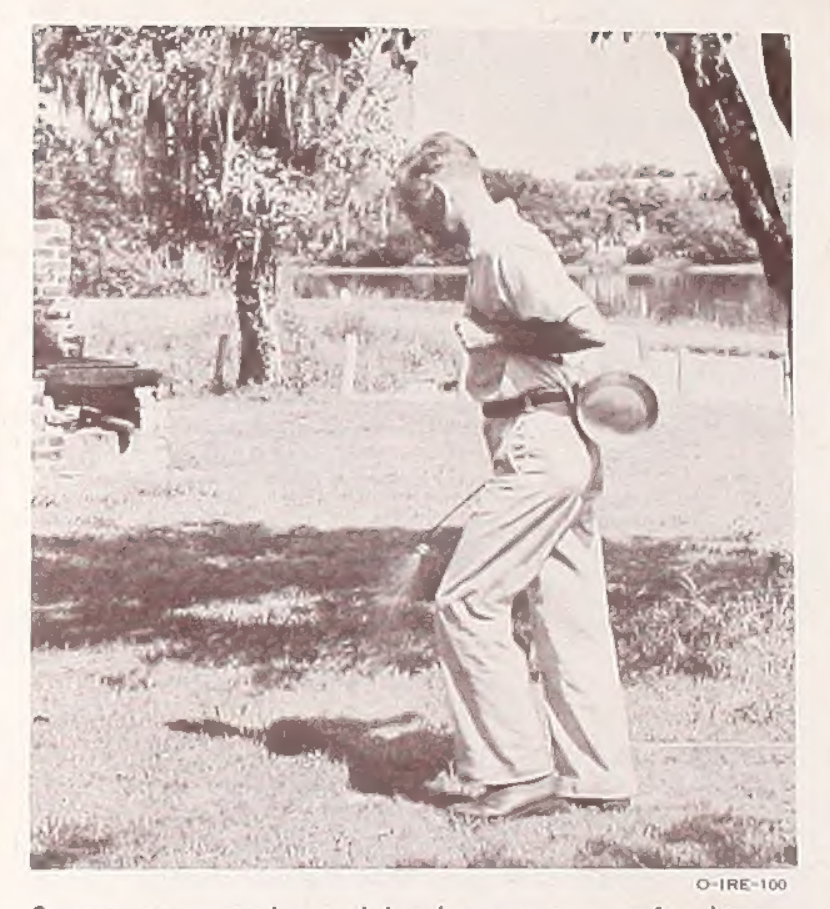

Spraying insecticide over lake shore pienic area for chigger 


\section{HOW TO PREPARE SPRAYS FOR CHIGGER CONTROL}

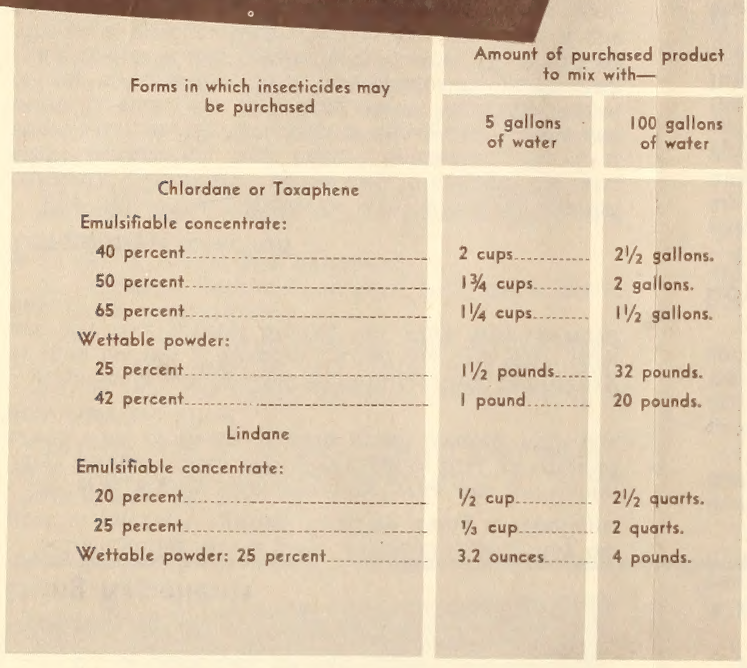

\section{Precautions}

\section{Repellents}

Do not treat underwear with a repellent. Treated underwear may irritate the skin.

Do not apply a repellent to stockings or other clothing that contains rayon. Repellents are damaging to rayon and to some other manmade fibers; nylon is not damaged.

Do not let repellents touch painted surfaces or objects made of plastic materials, such as fountain pens, fishing rods, watch erystals, or frames of eyeglasses.

\section{Insecticides}

Chlordane, toxaphene, and lindane are poisons. Handle them with care. Wear heavy clothing when you apply them. If an emulsifiable concentrate spills on your skin, wash it off at once with soap and water.

Avoid breathing the spray or dust. Spray or dust with the wind.

Keep children and pets out of a treated area until the spray dries.

After treating a lawn, sprinkle it with water to wash the insecticide from the grass into the soil. This reduces the hazard to children and pets, and does not reduce the effectiveness of the treatment.

Do not allow livestock to graze on a treated area within 2 weeks after the treatment.

Do not apply insecticides where they will contaminate fruit or vegetables.

To avoid killing fish, do not apply toxaphene along the margins of lakes or ponds, or along the banks of streams. Lindane or chlordane may be used in these places, but avoid contaminating the water.

Do not apply insecticide to your skin or your clothing to repel or kill chiggers; use only recommended repellents in this way.

\section{UIIIIE}

\section{- Development}

Adult chiggers pass the winter in protected places and become active in the spring. A few days after the females become active they lay their eggs in sheltered places. These eggs hatch into the first generation of the year.

The young chigger is known as a larva. It is the troublemaker. It is parasitic, feeding on man and animals. The larva transforms to a nymph, and the nymph to an adult. Neither the nymph nor the adult is a parasite.

Chiggers raised experimentally complete the life cycle-from egg to egg-in about 50 days.

In southern Florida and southern Texas, chiggers may be present throughout the year. In other States, the chigger season begins in May, June, or July and lasts until September or the first frost.
The bodies are hairy. A larva nas tnree pairs or legs. Its mouth parts include two pairs of grasping palps, which are provided with forked claws.

The nymphs and adults have four pairs of legs. The bodies are hairy, about $1 / 20$ inch long, and usually a brilliant red. There is a marked constriction in the front part of the bodies.

\section{- Feeding Habits}

Young chiggers attach themselves to the skin of people or to the skin of domestic animals, wild animals (including reptiles), poultry, and birds.

Before settling down to feed, chiggers scurry around for a suitable location. The preferred locations on people are those parts of the body where clothing fits tightly over the skin, or where the flesh is thin, tender, or wrinkled.

Like ticks, they attach themselves by inserting their mouth parts in the skin-frequently in hair follicles or pores. They inject a fluid into the skin; 


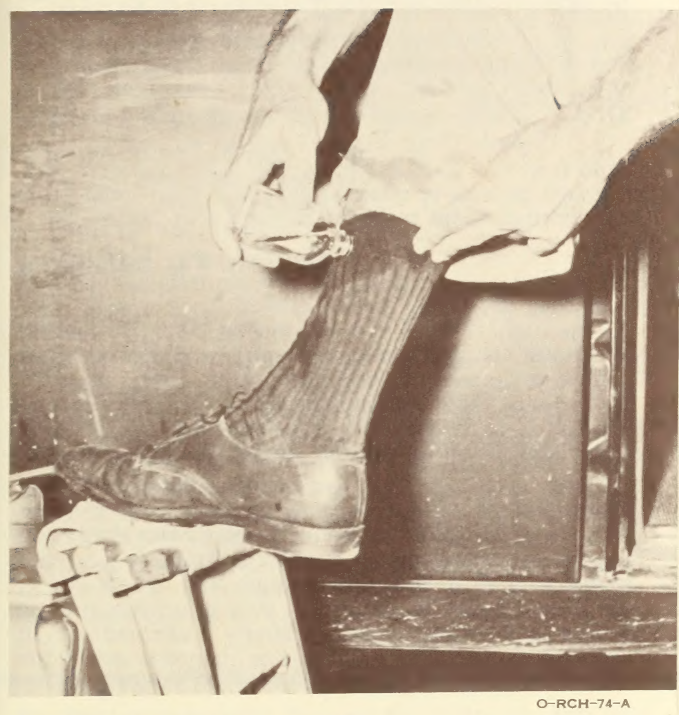

Applying repellent to socks and cuffs of trousers for protection against chiggers.

anu cirange u nyнups.

Nymphs and adults feed on insect eggs, small insects, and organisms found on or near woody decaying substances.

\section{- Effects of Attack}

The fluid injected into the skin by the chiggers causes reddish welts to appear. It also causes swelling, itching, and (in some persons) fever. Chigger bites have a more severe effect on some persons than on others. Persons who are exposed repeatedly may develop immunity to the bites.

A chigger attached in a pore or at the base of a hair may be so enveloped in swollen skin that it appears to be burrowing into the skin. This fact sometimes leads persons to believe, mistakenly, that chiggers embed themselves in the skin, or that welts contain chiggers.

Any welts, swelling, itching, or fever will develop within 24 hours after the attack. Itching may be intense and, if nothing is done to relieve it, may con-

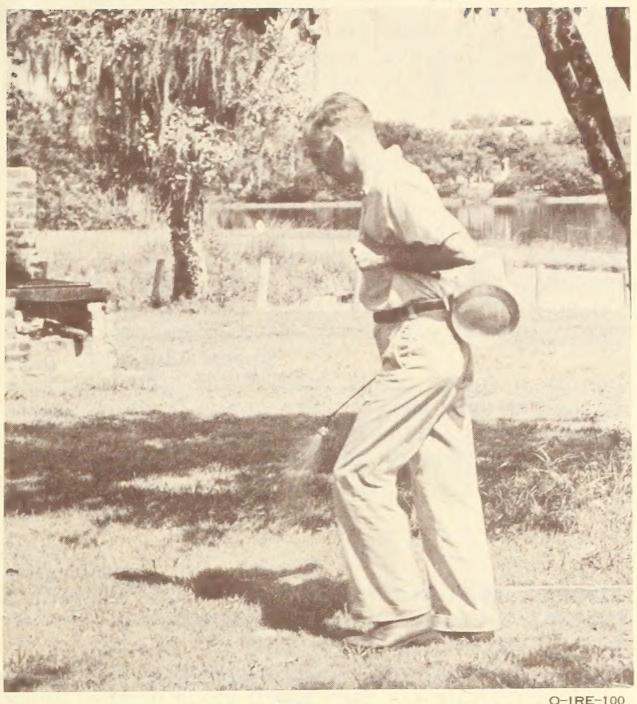

Spraying insecticide over lake shore picnic area for chigger control.

deaun or young cnickens."

Chiggers are not known to transmit any disease in this country. In some parts of the world, particularly in parts of the Far East, they transmit scrub typhus, a serious disease similar to spotted fever. In this country spotted fever is transmitted by ticks.

\section{- Infested Places}

Chiggers are most often found in low, damp places where vegetation is rank-for example, berry patches, orchards, woodlands, and margins of lakes and streams. But some species are adapted to living in drier places where vegetation is low, and heavy infestations may be found in lawns, golf courses, and parks.

You cannot tell by looking at a place whether it is infested. Chiggers may be numerous in a place one year, and scarce or absent another year; and they occur in some places only for short periods.

${ }^{2}$ See Leaflet 383, Poultry Mites: How To Control Them, which may be ${ }^{2}$ See Leaflet 383 , Poultry Mites: How To Control Them, which may be
obtained from the U. S. Department of Agriculture, Washington 25, D. C. 


\section{Using Repellents}

Before going into a place where chiggers may be Several highly effective repellents are available. crawl over clothing or skin areas treated with the Repelients can be used to obtain either temporary or long-lasting protection. Used the first way, the days.

\section{Temporary Protection}

The following repellents are effective against ethyl hexanediol, and benzyl benzoate. The first three are also effective against mosquitoes and some tor to a drug store, hardware store, for any one of the repellents by name. You may be fffered a product that contains two or more of the repellents. Such a product is acceptable. The repe

Apply the repellent to clothing by rubbing it on ing applying it directly from the bottle, or by spraymay be harmed by the repellent; nylon, cotton, and

Apply the repellent lightly, with the fingers, to the

Apply a ring of repellent just above your shoe tops. Treat all the way around the upper edges of the hos. Cotton and wool socks absorb repellent better than other materials and are preferred for wearing in chigger-infested places.

In treating other clothing, apply the repellent along treating openings that are buttoned, zippered, therwise fastened, treat such openings as the following:

In trousers and slacks.-Cuffs and waistband.
In shirts and blouses.-Cuffs (or armholes) and In skirts.-Hem and waistband.

In dresses, - Neckline and skirt hem; cuffs, sleeve

To rub a repellent on clothing, pour about a dozen together, then rub lightly the parts of the clothing to To apply it directly from the bottle, press the botthe opening against the clothing and move it over the parts to be treated.

\section{To spray a repellent on clothing, use an ordinary
Sproying the Clothing}

Do not saturate the cloth with repellent. If a garment is moist with repellent along all openingsIf the infested place is one in which the vegetation is low, if you intend merely to walk in it, and if you are wearing trousers or slacks, you need only apply socks or stockings.

\section{Long-Lasting Protection}

Long-lasting protection against chiggers is needed chiefly by men who work regularly in infested areas hunters-who may be in such areas several days at The protection is obtained by impregnating clothuted repellent on the clothing. Use dimethyl phthalate or benzyl benzoate.

Impregnating the Clothing

Two ounces of repellent in a solution or emulsion
are needed to treat an ordinary set of work clothesPrepare a solution by adding the repellent to 1 Prepare an dry-cleaning fluid.

of soap powder (but not synthetic detergent) the water is soapy 1 quake 1 cupful of the soapy (3) Pour this into the rest of the soapy water and stir vigorously.

Multiply these quantities by 2 if you are going to treat 2 sets of clothes, by 3 if you are going to treat
3 sets, and so on. Place the clothes in a container and slowly pour in the liquid. Wet them uniformly but do not let them soak. Wring them and hang them out to dry. week, unless it is washed out of the clothing. Laundering washes out the repellent; a heavy rain may do so. Repellent in trousers and socks is washed out if

Benzyl benzoate is effective longer than dimethy protection even after clothing has been laundered twice. Clothing that has been laundered twice since

In addition to providing complete protection against chiggers, either of these treatments gives are needed to treat an ordinary set of work clothesthinly sliced soap in 1 quart of water and stir until water, add the repellent, and stir vigorously. Dimethyl phthalate gives protection for at least a ing after each laundering. being treated should be re-treated. to the openings. Using a hand sprayer, apply a mist until the clothing is slightly moist, but not wet. Do not apply more than 2 ounces of repellent to a set of work clothes. Let the clothes dry for several hours before wearing them.

It is easier to spray clothes than to put them cult to apply the spray uniformly. Also, sprayed-on than repellent applied by impregnation, and it is

\section{Reducing the Itching}

If you get in a chigger-infested place without the You may not know that you have been attacked until welts appear on the body and itching begins.

Take a bath as soon as possible. Apply a thick bath kills most, or all, of the attached chiggers, and Next, apply a dab of antiseptic to each of the weits. it aids in preventing infection. Destroying the chiggers reduces the itching, but causes the iteh. The fhiggers it has been found, and no treatment is known the will give permanent relief from the itching.

To get temporary relief, apply a local anesthetic. Benzocaine, 5 percent.

Methyl salicylate, 2 percent.

Salicylic acid, 0.5 percent.

Water, 19.5 percent.

Take the formula to your druggist for compoundlonger. Repeat the treatment as often as necessary. Some persons who have had experience with chigwelts and itching. They feel the slight irritation of is produced when the chiggers begin to attach, and movement of chiggers as they crawl on the body seeking a place to attach.

If you become aware of sensations that cause you Look carefully at the bases of hairs. You may not be
In spraying to obtain long-lasting protection, you
apply the repellent to the entire garment- not just of undiluted dimethyl phthalate or benzyl benzoate any others that may not yet be attached. ing. Apply the material to each welt with a piece of

able to see the chiggers, but you may be able to see The more quickly you detect the chiggers, the betan take the bath within the soapy bath. If y get on you, it will probably kill most of them before

\section{Using Insecticides}

You can wipe out a chigger infestation by appl infested area. round themay or dust to grass, logs (and the ground bushes and high weeds.

The recommended insecticides are chlordane, toxasecticide supply stores, and are generally availab in the form of emulsifiable concentrates, wettable cides, and decide in what form you wish to purchase An emulsifiable concentrate or wettable powder is mixed with water to make a spray. A dust is ready

An emulsion spray, prepared by mixing an emulsifiable concentrate with water, usually gives bet
results than a wettable-powder spray or a dust.

\section{Locating the Chiggers}

Before you start applying an insecticide, have a a large one, such as a picnic ground, a golf course, or survey. The chigrers may be concentrated in a few spots within the area. Treating the trouble spots is quicker and less expensive than treating the whole Place a piece of black cardboard edgewise on the ground. Observe it for a few minutes. If chiggers gregate there. Make the test in about a dozen spots over the area. Pick out spots that have different kinds of cover, such as solid growths of grass, tufts of grass, dead leaves, and decaying twigs. Rememby a repellent.

If experience has already shown that the entix area is infested, go ahead and treat all of it, witho which control is especially desired, such as grass and hrubbery around pienic tables or lawn chairs.

Sprays

Emulsifiable concentrates and wettable powder the fluid dissolves the tissues; the chiggers suck up liquefied tissue.

When they attach themselves to animals, they beand change to nymphs.

Nymphs and adults feed on insect eggs, small insects, and organisms found on or near woody decaying substances.

The nymphs and adults have four pairs of legs. The bodies are hairy, about $1 / 20$ inch long, and usually a front part of the bodies.

\section{- Feeding Habits}

Young chiggers attach themselves to the skin of people or to the skin of domestic animals.

Before settling down to feed, chiggers scurry around for a suitable location. The preferred locations on people are those parts of the hor the flesh is thin, tender, or wrinkled.

Like ticks, they attach themselves by inserting their mouth parts in the skin-frequently in hair
follicles or pores. They inject a fluid into the skin;

\section{- Effects of Attack}

The fluid injected into the skin by the chiggers causes reddish welts to appear. It also causes swell bites have a more severe effect on some persons than on others. Persons who are exposed repeatedly may develop immunity to the bites.

A chigger attached in a pore or at the base of a
hair may be so enveloped in swollen skin that it appears to be burrowing into the skin. This fact sometimes leads persons to believe, mistakenly, that chigger's embed themselves in the skin, or that welts contain chiggers.

Any welts, swelling, itching, or fever will develop within 24 hours after the attack. Itching may be the skin and result in infection.

Chiggers attacking in large numbers can cause serious injury to poultry.

Chiggers are not lunown to transmit any disease in this country. In some parts of the world, particularly in parts of the Far East, they transmit scrub typhus, a serious disease similar to spotted fever.
country spotted fever is transmitted by ticks.

\section{- Infested Places}

Chiggers are most often found in low, damp places where vegetation is rank-for example, berry and streams. But some species are adapted to living in drier places where vegetation is low, and heavy parks.

You cannot tell by looking at a place whether it is infested. Chiggers may be numerous in a place one year, and scarce or absent another year;
occur in some places only for short periods.

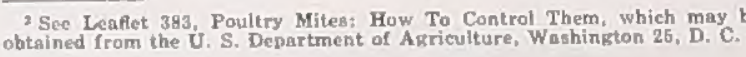
may be present throughout the year. In other States, the chigger season begins in May, June, or July and 
centages shown in the accompanying chart are those most commonly found in retail products.

To prepare a spray, mix one of the products with water in the proportion indicated in the chart. Apply the finished spray as follows:

Small areas. - To treat a lawn, campsite, or other small area, use a cylindrical compressed-air sprayer or a knapsack sprayer. Apply $2 \frac{1}{2}$ to 3 quarts per 1,000 square feet (25 to 35 gallons per acre).

Large areas.-To treat a park, golf course, or other large area, use a power sprayer. To get uniform coverage, apply twice as much spray material as you would with a small sprayer, but do not add insecticide. Double the amount of spray material by adding water. Apply 50 to 70 gallons per acre.

An emulsion spray prepared and applied according to these recommendations is effective 4 to 8 weeks; a wettable-powder spray, 2 to 6 weeks. A spray is considered effective for a stated period if few or no active chiggers can be found in the treated area during that period.

\section{Dusts}

Apply 5-percent chlordane or toxaphene dust at the rate of 40 to 50 pounds per acre ( 1 to $1 \frac{1}{4}$ pounds per 1,000 square feet), and 1-percent lindane dust at the rate of 25 to 50 pounds per acre (10 ounces to $11 / 4$ pounds per 1,000 square feet). A dust treatment is effective 1 to 4 weeks.

Dusts can be applied with any equipment that is used for dusting plants. A rotary hand duster is excellent for treating small areas. A power duster is better for large areas.

If you have any questions about the repellents or insecticides discussed in this leaflet, consult your county agent or an entomologist in your State extension service or experiment station; or write to the Entomology Research Branch, Agricultural Research Service, U. S. Department of Agriculture, Plant Industry Station, Beltsville, Md.

This leaflet was prepared by the Entomology Research Branch, Agricultural Research Service. It supersedes Leaflet 302, Chigger Control.

Washington, D. C.

Issued March 1956

For sale by the Superintendent of Documents, U. S. Government Printing Office, Washington 25, D. C. - Price 5 cents 